Artes Plásticas e Letras

A4) 


\title{
A COMPleXizaÇÃO DO OBJETO ARTíSTICO \\ uma análise da obra de Angela lago
}

\author{
André Mendes \\ Doutorando em Literatura Comparada, Faculdade de Letras/UFMG
}

\begin{abstract}
RESU M O
Esse artigo pretende defender a idéia de que as ilustrações produzidas por Angela Lago, por serem sistemas complexos, são capazes de acrescentar ao texto escrito ao qual reportam um maior número de significados, ampliando as possibilidades de leitura dessas obras, enriquecendo-as como objeto artístico.
\end{abstract}

\section{PALAVRAS - CHAVE}

Literatura juvenil, ilustração, sistema complexo, ruído

\section{ENCONTROS}

Quase que por acaso, chega às minhas mãos um livro de histórias infantis. Abro o livro imediatamente e, já na primeira página, sou convidado a uma brincadeira. A morte ri para mim e tira, literalmente, sua roupa. Encantado, adianto a leitura do livro e percebo que o autor trabalha o texto e a imagem com desenvoltura e complexidade, ao mesmo tempo, com uma "facilidade" que me encanta. Procuro pelo autor e encontro mais de um nome: Angela Lago, com uma pequena ajuda de Dürer. Não preciso pesquisar muito para descobrir que Angela Lago é uma premiada artista, no Brasil e no exterior, escritora e ilustradora que não se contenta em pensar a imagem gráfica como uma representação explicativa do texto original, fazendo questão de inserir o seu comentário nas imagens que produz, de uma forma delicada e bela.

Esse encontro com a obra de Angela Lago aconteceu no final dos anos 90 e foi tão marcante que decidi escrever a minha dissertação de mestrado baseando-me no seu trabalho. ${ }^{1}$ Durante o período em que tive o prazer de me envolver com vários livros dessa artista, pude confirmar minha intuição de que ela não era uma ilustradora comum. Sempre cuidadosa e consciente ao produzir suas

${ }^{1}$ A complexização do objeto artístico: uma análise da obra de Angela Lago. Essa tese foi vencedora do Prêmio Moinho Santista Juventude e publicada pela Editora UFMG em 2002.

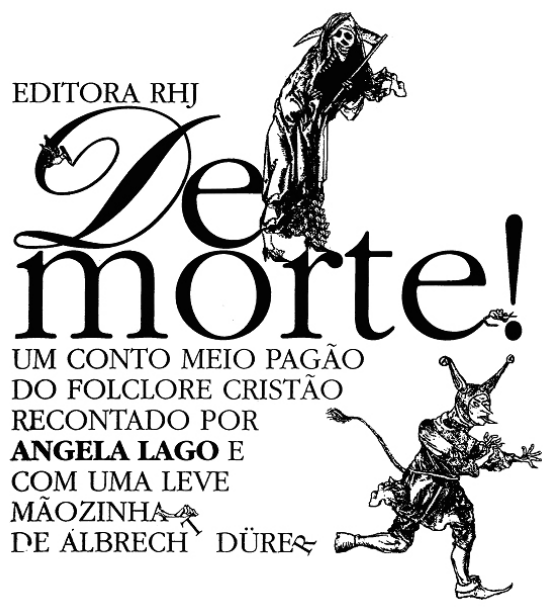


imagens, Angela insere elementos que não estão contidos no texto impresso e que apontam para outras referências, diferentes do texto original. Essas inserções (que podem ser citações a outros autores, histórias paralelas, uma caracterização dos personagens, etc.) aumentam a rede de relações possíveis entre os elementos da ilustração e a história.

Por meio dos seus comentários gráficos e narrativos, Angela Lago acaba por gerar uma ilustração que não é apenas a explicação do conteúdo do texto impresso original, mas o diálogo dessa artista com esse texto e com o mundo. Ao optar por não realizar uma ilustração tradicional, que fixaria os significados do texto numa direção interpretativa determinada, essa artista deixa espaço para o acaso e para a subjetividade do leitor, transformando o livro num sistema ainda mais complexo e tornando o texto original mais rico de possibilidades interpretativas. Assim, as ilustrações produzidas por Angela Lago não apenas agregam um valor estético a um texto escrito, mas também ampliam as possibilidades de leitura desse texto, enriquecendo-o como objeto artístico.

\section{COMPLEXO NÃO É SINÔNIMO DE COMPLICADO}

O conceito de complexo aqui referido não tem a ver necessariamente com aquele associado à idéia de difícil ou de complicação, mas sim ao significado que o termo adquiriu ao ser utilizado pela cibernética, nos anos 60, e que, mais tarde, nos anos 90, será aproveitado por Edgar Morin para desenvolver suas idéias sobre as mudanças de paradigma nas ciências. O conceito de sistema complexo refere-se aos sistemas cujos componentes interagem de forma tão intrincada que sua composição final não pode ser prevista por meio de equações lineares. Dizer que um sistema é complexo, sob esse ponto de vista, não significa dizer que ele é complicado, mas sim que tem um grande número de unidades interagindo entre si de formas imprevisíveis. Em vez de soma, o que acontece é uma integração na qual as partes se relacionam mutuamente e na qual a forma dos relacionamentos é de suprema importância para o todo emergente. Essa integração tem caráter qualitativo e se fundamenta em processos recíprocos e reiterativos, isto é, não-lineares e, por isso mesmo, nem sempre mensuráveis, previsíveis ou programáveis. Assim, o todo não será definido pela somatória das partes, mas pela configuração que o sistema possui num determinado momento.

Ao analisar algumas obras de Angela Lago, pude perceber que há, no seu processo ilustrativo, pelo menos dois tipos de complexização da imagem que merecem uma maior atenção e estudo: a complexização que pode se dar por meio da síntese e a complexização que pode se dar por meio do caos - mas não um caos qualquer, e sim um caos que permite ao leitor alguma espécie de ordenação (um caos simulado). Na complexização por caos, há um aumento da entropia do sistema (da ilustração), o que cria possibilidades interpretativas de uma forma mais indeterminada (o aumento da entropia dá espaço para o acaso agir de uma forma mais livre). Já na síntese, a possibilidade de várias leituras é menor do que na complexização por caos porque as escolhas do ilustrador podem fixar um pouco mais os caminhos interpretativos numa direção determinada. É importante salientar também que a imagem sintética pode ser utilizada em outras composições, inclusive em imagens caóticas, de forma a ajudar na formação de um caos mais complexo. Isso nos leva a concluir que uma imagem pode comportar os dois processos ao mesmo tempo. 


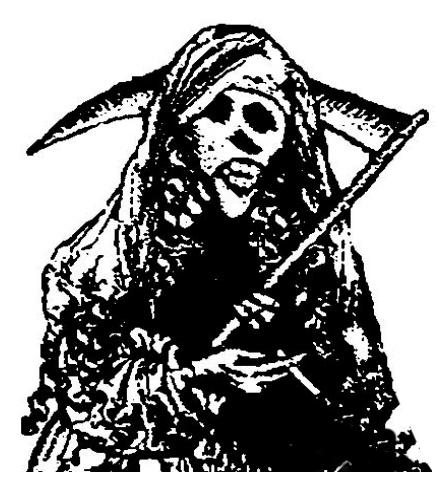

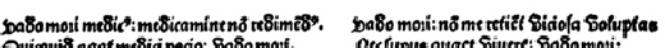

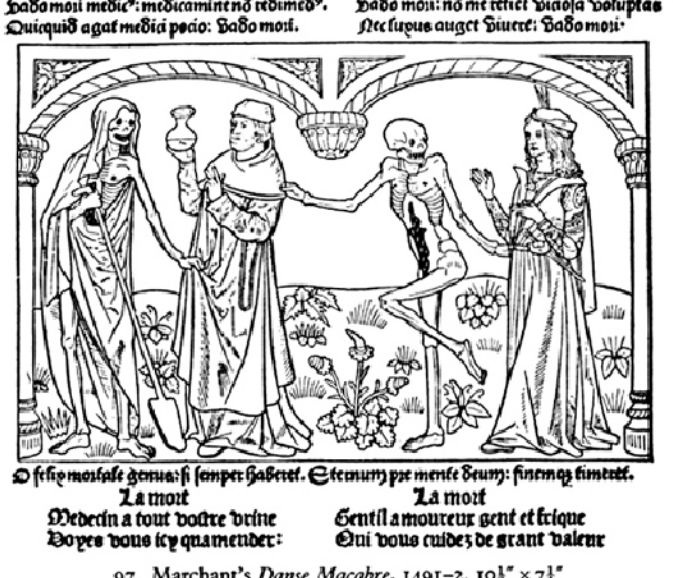

97. Marchant's Danse Macabre, $149 \mathrm{I}-2 . \mathrm{rO}^{\prime \prime} \times 71^{\prime \prime}$

Nesse artigo vou analisar ilustrações de dois livros dessa premiada autora: De morte e o Cântico dos Cânticos. Nesses livros existem bons exemplos dessas variações de imagens complexas. De morte, escrito em 1992, conta a história de um velhinho que engana a Morte e o Diabo para não morrer. O livro, pensado para crianças a partir de 9 anos, foi criado com base em histórias sobre morte e o diabo do folclore português e espanhol, além da nossa literatura de cordel.

A representação da Morte no livro De morte é um bom exemplo de complexização por síntese. A artista, ao compor uma figura representativa da morte, fundindo à imagem tradicional (gótica) ratos, cigarros, partes de mulher e expressões humanas, amplia o campo original de interpretantes possíveis que essa imagem tinha potencialmente. Se por um lado, a figura da Morte que a autora constrói mescla elementos tradicionais como manto negro, ossos e foice - combinação que ressalta as características "negativas" desses ícones -, ao sintetizar nessa composição outros signos como o cigarro, os ratos, as pernas de mulher e a expressividade da face (que varia entre riso e sofrimento), pode levar o leitor a um espanto, um certo estranhamento que o motivará a repensar seu conceito de Morte.

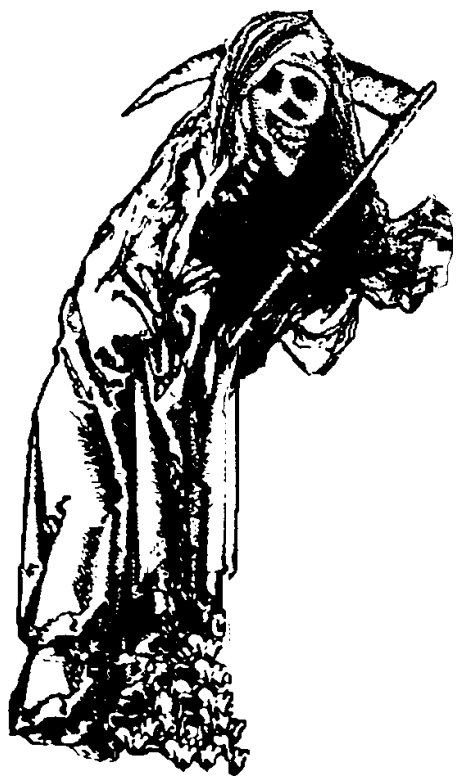

A imagem tradicional da morte normalmente direcionaria os sentidos interpretativos para um caminho bastante restrito e não acrescentaria muito à narrativa. Angela Lago, ao sintetizar uma figura da Morte em que signos tradicio-

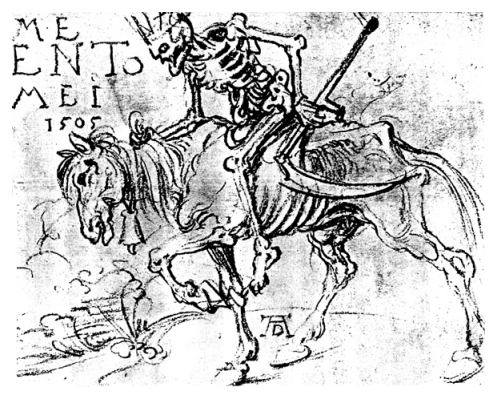

A. Dürer, "memento mei”, 1505 nais e outros, nem tão tradicionais, são combinados, reconstrói a retórica desse ícone tornando-o mais rico, ampliando o campo de produção de sentidos do leitor e exigindo-lhe mais do que uma leitura "simples". 


\section{CÂNTICO DOS CÂNTICOS: A COMPLEXIZAÇÃO POR CAOS}

Já o projeto de ilustração do Cânticos dos Cânticos, uma história de amor bíblica, foi mais ousado e complexo, consumindo, em sua produção, algo em torno de oito anos, desde os primeiros esboços até a versão final. Segundo Angela, várias bíblias foram lidas, mas a de Jerusalém, editada pela Editora Paulinas, foi a mais utilizada como referência para seu trabalho. Além

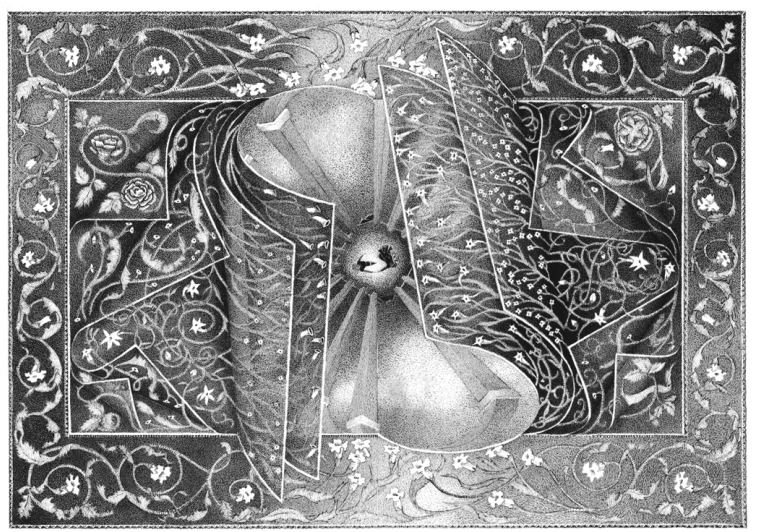

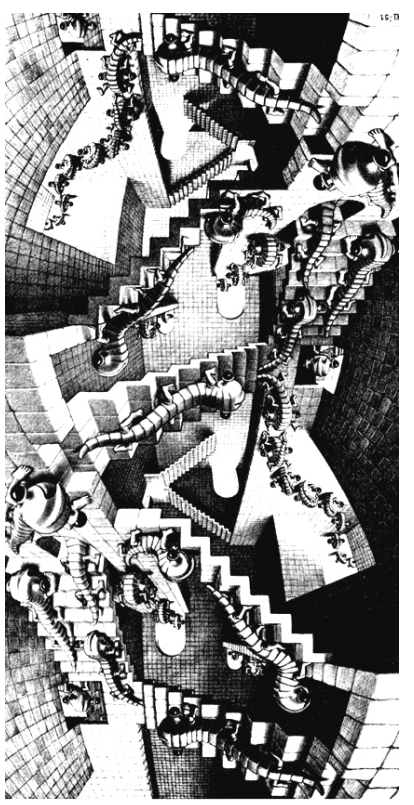

House of stairs - Escher dessas bíblias, Angela destaca que o Cântico dos Cânticos, de Frei Luís de Leon, também foi uma importante referência. Durante a maior parte do trabalho, sua idéia era usar fragmentos de texto dos Cânticos no topo das páginas pares e na base das páginas ímpares, de maneira a ter a voz masculina de um lado e a feminina do outro, uma de ponta-cabeça em relação à outra. Apesar de ter sido criado para jovens leitores a partir dos 12 anos, o livro alcança uma faixa etária muito maior, provavelmente, devido às várias camadas de sentido que constituem a obra e permitem que tanto um público juvenil quanto um público adulto possa ter prazer em penetrar nesse labirinto de imagens.

O Cântico dos Cânticos é um bom exemplo de complexização por caos. Nessa obra, Angela Lago oferece ao leitor grande número de possibilidades interpretativas, obrigando-o a lidar com uma série de variáveis ao mesmo tempo. As palavras do texto original (todo o texto impresso) foram transformadas em imagens cheias de cores e de citações, uma sinfonia figurativa na qual é possível perceber referências a Van Gogh, ao Barroco, às iluminuras medievais, aos labirintos que fazem parte da poética de Jorge Luis Borges e de M. C. Escher.

Nesse livro, que pode ser lido do início para o fim ou do fim para o começo, na posição normal ou de cabeça para baixo, as páginas foram compostas para serem lidas em pares. Na parte central das duas folhas, onde deve estar a narrativa principal, acompanhamos os personagens por uma construção que pode ser um palácio ou um labirinto - ou os dois. Vemos uma mulher (uma princesa?) e um homem (um arquétipo do homem, do amante?) e nos perguntamos: qual a

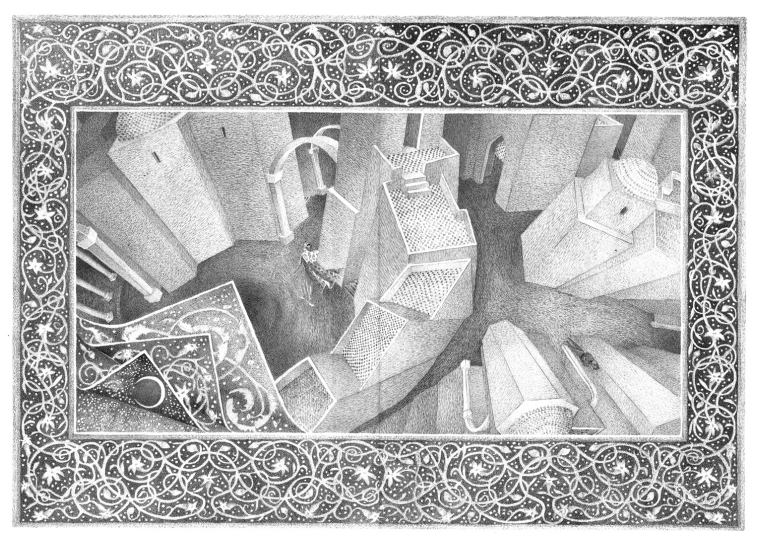


relação entre eles? Se movermos as páginas numa direção, podemos construir uma história, a história do homem. Se movermos na direção contrária, é possível pensar outro enredo, a história da princesa. Se prestarmos atenção às bordas, perceberemos que elas se modificam a cada página. Qual a relação das bordas com a história principal? Seriam essas bordas a representação de algo relacionado à história do homem ou da mulher, ou da relação de ambos, ou ainda, de tudo isso junto? Teriam as bordas uma narrativa própria?

A arquitetura, as roupas e também a lua remetem à magia

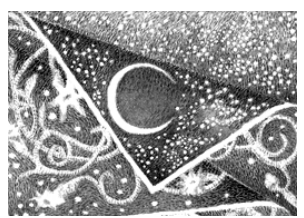
da Arábia, ao Oriente - o leitor pode se deixar levar pela atmosfera das mil e uma noites. Se o leitor conhece a história do Cântico dos Cânticos, então é natural que fique confuso a princípio, principalmente pela transformação das palavras na sinfonia barroca de imagens gráficas e, depois, ficará ainda mais confuso com o desfecho da história que, de certa forma, não termina. Para encontrar a solução do mistério, terá de buscar outras relações de significação além daquelas que ele já conhece. O leitor tem de lidar com várias possibilidades de escolha ao mesmo tempo, às vezes, não criará um sentido linear, às vezes, deixar-se-á penetrar pelas imagens, fruindo sem tentar achar um enredo tradicional, com princípio, meio e final. A maneira como foi idealizado o livro, sem início nem fim, incentiva esse comportamento na medida em que possibilita ao leitor uma série quase infinita de leituras, de interpretações, para o mesmo conjunto de ilustrações.

\section{O RUÍDO COMO UM RECURSO DE COMPLEXIZAÇÃO}

Outro ponto interessante a ser destacado no processo de complexização de Angela Lago é a utilização do ruído como recurso poético. Ao acrescentar referências (inclusive misturando linguagens), a autora gera aquilo que podemos chamar de uma espécie de "ruído" na leitura. Exatamente o ruído que, por gerar ambigüidade, muitas vezes é considerado como um elemento negativo num sistema de comunicação, na obra de Angela Lago tem um papel fundamental: funciona como recurso poético para ampliar as possibilidades de leitura da obra.

Para entender melhor essa afirmativa, é importante lembrar que a leitura de um texto se dá numa relação em que a subjetividade do leitor, em contato com os signos oferecidos pelo objeto (e pelo ambiente num determinado momento), inicia um processo de decifração (ou criação de representações) no qual o significado será formado ao término desse processo. A existência de ruídos criará uma instabilidade na leitura, permitindo a possibilidade de que os signos sejam interpretados de forma diferente do que é convencionalmente esperado e, dessa forma, a chance de que novos interpretantes sejam gerados a cada leitura é aumentada.

Tal como um quebra-cabeça cuja imagem só será completa ao adicionarmos a última peça, os signos que compõem uma narrativa podem ser pensados como pequenas peças de significação que são unidos à medida que vamos lendo (virtualmente falando) e que, conforme montamos o quebra-cabeça, vão dando novas pistas de onde devemos encaixar as peças seguintes. Ao finalizarmos essa operação de montagem, a união dos signos produzirá uma imagem que pode se tornar mais rica do que a soma de cada signo, 
individualmente. O ruído criador que essa artista produz gera, durante a leitura, uma ambigüidade na construção desse quebra-cabeça que pode criar mais instabilidade no encaixe das peças, ao mesmo tempo em que lhes dá uma maior maleabilidade, permitindo ao leitor compor o quebra-cabeça com maior espaço para a sua subjetividade.

Conversa vai, conversa vem, a Morte finalmente deixou o velho rezar s um único Padre Nosso. Có ele foi rezando tão, tão devagar, que a Morte, cansada de esperar, sentou na beirada da of cama.

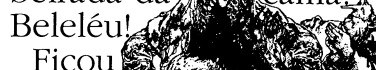
Ficou grudada?

\section{O RUÍDO EM DE MORTE}

Nos livros analisados nesse artigo, vários são os ruídos utilizados

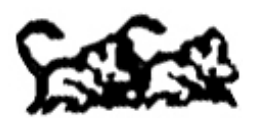
por Angela Lago. Um bom exemplo é o desaparecimento do texto e a subversão da ordem tradicional de leitura em o Cântico dos Cânticos (que já foram comentados nesse artigo) e a inserção de uma história paralela em De morte. Em De morte, podemos observar nas "bordas" da história principal (na qual o velhinho luta contra a Morte e o Diabo), uma luta dos pássaros e dos gatos contra os ratos. $\mathrm{O}$ fato de existir uma história paralela à principal pode dar a impressão de uma certa desordem na narrativa, mas essa desordem é apenas uma simulação, já que essa história secundária, apesar de ser independente, pode se relacionar diretamente com a história principal, representando a eterna luta do "bem" contra o "mal".

Não é necessário muito esforço para perceber essa relação: os ratos são seres que habitam a terra, a escuridão, enquanto os pássaros vivem no céu. Nos desenhos, os ratos fazem parte da imagem da morte, do corpo da morte, e os pássaros fazem parte das portas do céu. $O$ fato de os ratos estarem fundidos na imagem da Morte permite que pensemos

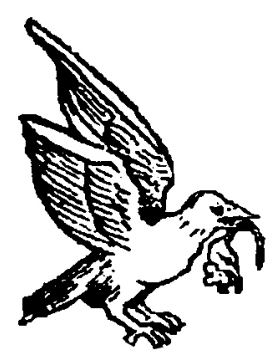
neles como provenientes da morte, representando-a por metonímia. Podemos usar o mesmo raciocínio para os pássaros: pelo fato de fazerem parte das portas do céu, seriam representantes da "celestidade". Os ratos, a Morte e o Diabo representariam o Mal, enquanto os pássaros e os gatos (principalmente por serem exterminadores de ratos) representariam o Bem. Do mesmo modo que o velhinho luta contra a Morte e o Diabo, o gato e os pássaros lutam contra os ratos.

O ruído que Angela Lago produz, apesar de não contribuir para a economia da narrativa, de não servir especificamente para avançar a história, enriquece a obra em si mesma ao estabelecer liames entre o texto original e outros textos e, dessa forma, constitui uma nova rede num novo universo narrativo e textual acrescentado de novos caminhos, cômodos, alçapões e passagens no labirinto da leitura. Se a existência desses ruídos pode desviar a atenção do leitor para outros assuntos que não são o texto em si, causando até uma certa desorientação, eles também tornam possível ao leitor movimentar-se de acordo 
com seu desejo no texto. Além disso, essa desorientação que o ruído pode vir a gerar é uma desorientação relativa, pois, ao mesmo tempo em que os ruídos apontam outras possibilidades de significação, se não forem percebidos, ou no caso do leitor não aceitar o jogo, esses elementos podem ser deixados de lado, descartados da história, sem interferir de uma forma determinante na leitura da história principal, tal como links não ativados.

\section{UMA ILUSTRADORA COMPLEXA}

A forma como Angela Lago produz suas ilustrações reflete uma postura diante da arte e do objeto artístico que considera o leitor não como um sujeito totalmente independente do texto, nem como sujeito preso às interpretações que ela, como artista, pretendeu, quando criou a obra. Essa postura está de acordo com uma forma de pensamento que considera ser possível ao leitor, por meio da sua subjetividade, interagir com a obra artística não apenas pela soma (de interpretantes), mas criando um novo objeto que terá sua forma final definida por essa interação e, ainda, pelas inferências externas e acontecimentos imprevistos. Essa visão considera que o objeto artístico não é

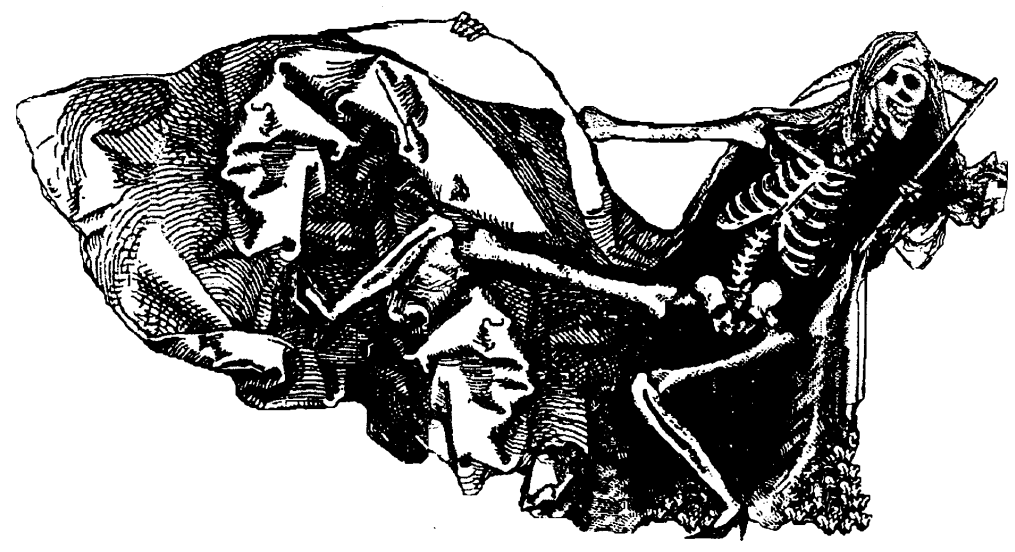
nem o texto objetivo nem a experiência subjetiva, mas o esquema virtual constituído na interação entre o objeto e o leitor, feito de lacunas, de buracos e de indeterminações.

Angela Lago, assim como outros ilustradores que optam por produzir um desenho complexo,

pode frustrar as expectativas do leitor que espera uma ilustração esclarecedora do texto impresso (ilustração tradicional). Ao invés disso, oferece ao leitor um conjunto de imagens que lhe permitem criar sentido para novas representações ou que o estimulam a impor ordem em uma espécie de caos interpretativo por ela apresentado. O leitor, ao percorrer os vários caminhos, os novos e diversos níveis do labirinto criado por essa artista, se encontra diante de um sem-número de dados, não sucessivos nem lineares, que se superpõem, desaparecem e retornam, ora simultâneos, ora intermitentes, criando um verdadeiro emaranhado de relações na rede textual, e esse ato gera novas saídas e entradas para a intepretação.

Diante desse universo complexo, o leitor pode ou não estabelecer relações, pode ou não reconhecer(-se) (n) uma citação, uma história paralela etc. O leitor é livre para escolher entrar ou não no labirinto da leitura, mas se aceita o desafio, se "firma o pacto", penetrará num lugar sem regras fixas em que a subversão dessas regras faz parte do jogo; qualquer coisa pode ser tudo; as paredes, os caminhos, nada é definitivo, sendo construído ou reconstruído pelo leitor à medida que ele avança no labirinto, na sua busca. 


\section{A B S T R A C T}

This essay argues that Angela Lago's illustrations, being complex systems, will enrich the text of her books by adding new meanings and increasing the ways they can be interpreted.

\section{KEYWORDS}

Juvenile literature, illustration, complex system, noise

\section{REFERÊNCIAS}

ESCHER, Maurits Cornelis. The World of M. C. Escher. Amsterdam: Meulenhoff International, 1971.

LAGO, Ângela. O Cântico dos Cânticos. São Paulo: Editora Paulinas, 1992.

LAGO, Ângela. De morte. Belo Horizonte: RHJ, 1992.

MENDES, André. O amor e o diabo em Angela Lago: a complexidade do objeto artístico. Belo Horizonte: Editora UFMG, 2007.

MORIN, Edgar. Introdução ao pensamento complexo. Lisboa: Instituto Piaget, 2001. 